respiration though small is easily measurable. Comparing the ratios of respiration, ærobic and anærobic glycolysis, we find roughly the same relationship for medulla of kidney, cartilage and tumours.

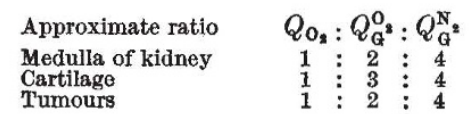

Thus cartilage gives further support to the view previously expressed ${ }^{2}$ that the metabolic type depends on the relationship between oxygen supply and energy requirements of the tissue.

$$
\begin{aligned}
& \text { F. DiCKens. } \\
& \text { H. WEIL-Malherbe. }
\end{aligned}
$$

Cancer Research Institute,

North of England Council of the

British Empire Cancer Campaign,

Royal Victoria Infirmary,

Newcastle on Tyne. July 3.

1 Bywaters, Nature, 138, 30 (1936).

Dickens and Weil-Malherbe, Biochem. J., 30, 659 (1936),

\section{Optical Polarization Ellipsoids of the Hydrogen Halide Gases}

Estimates of polarization and related constants of the four hydrogen halides ${ }^{1}$ appear to reveal certain peculiar, though simple relations. If $\alpha$ is the mean optical polarizability of a halide $\mathrm{HX}, b_{1}, b_{2}$ respectively that along and perpendicular to the internuclear axis of symmetry $S, r_{e}$ the equilibrium internuclear distance of $\mathrm{HX}$, and $\alpha(X)$ the polarisability of the negative ion $X^{-}$, I find that (1) $\alpha=1 \cdot 242 r_{e}{ }^{32,3}$ and, further, if (2) $b_{1} \propto r_{e}^{3}$, then since $3 \alpha=b_{1}+2 b_{2}$, (2a) $b_{2} \propto r_{e}^{3}$, (2b) $b_{1} \propto b_{2}$, and (2c) $b_{1}=\alpha(X)$ (Born and Heisenberg ${ }^{4}$ ).

Stuart ${ }^{5}$, arguing from the positive sign of the constant occurring in the electro-optical Kerr effect of hydrogen chloride, found that the direction of greatest polarisability $b_{1}$ coincided with the axis $S$, along which the permanent dipole also lies. If we take ${ }^{1}$ $\alpha(\mathrm{HCl})=2 \cdot 56$, and ${ }^{5}\left(b_{1}-b_{2}\right) \mathrm{HCl}=0.77 \times 10^{-24}$ c.c., it follows that $b_{1}, b_{2}$ are $3 \cdot 07$ and $2 \cdot 30 \times 10^{-24}$ c.c. respectively. Using the above assumption (2), the corresponding values for the other halides may be

\begin{tabular}{|c|c|c|c|c|c|c|}
\hline HX & \multicolumn{3}{|c|}{$\begin{array}{l}b_{1}, b_{2}, \frac{1}{3}\left(b_{1}+2 b_{2}\right) \\
\left.\text { (in c.c. } \times 10^{24}\right)\end{array}$} & $\begin{array}{l}a(\mathrm{HX}) \\
\left.(\text { expt. })^{\prime}\right)\end{array}$ & $\alpha(\mathrm{X})$ & $r_{e}$ \\
\hline $\begin{array}{l}\mathrm{HF} \\
\mathrm{HCl} \\
\mathrm{HBBr} \\
\mathrm{HI}\end{array}$ & $\begin{array}{l}0 \cdot 96 \\
3 \cdot 07 \\
4 \cdot 19 \\
6 \cdot 24\end{array}$ & $\begin{array}{l}0 \cdot 72 \\
2 \cdot 30 \\
3 \cdot 14 \\
4 \cdot 68\end{array}$ & $\begin{array}{l}0 \cdot 82 \\
2 \cdot 56 \\
3 \cdot 49 \\
5 \cdot 20\end{array}$ & $\begin{array}{l}0 \cdot 80 \\
2 \cdot 56 \\
3 \cdot 49 \\
5 \cdot 18\end{array}$ & $\begin{array}{l}0.99 \\
3 \cdot 05 \\
4 \cdot 17 \\
6 \cdot 28\end{array}$ & $\begin{array}{l}0.864 \mathrm{~A} . \\
1.272 \\
1.411 \\
1.612\end{array}$ \\
\hline
\end{tabular}
calculated, as in the following scheme.

The anisotropy $\delta$ is connected with the depolarization factor $\Delta$ (ratio of light intensity scattered parallel and at right angles to direction of incident beam) for gas molecules having an axis of symmetry, as follows :

$$
\delta^{2}=\frac{5 \Delta}{6-7 \Delta}=\left(\frac{b_{1}-b_{2}}{b_{1}+2 b_{2}}\right)^{2}=\frac{1}{9}\left(\frac{b_{1}-b_{2}}{\alpha}\right)^{2},
$$

so that we have $\delta^{2}=0 \cdot 01007, \delta=0 \cdot 1004$ and $\Delta=0.0119$ for each of the four cases. (Stuart ${ }^{5}$ found $\Delta(\mathrm{HCl})=0.0125$, giving $b_{1}=3.01, b_{2}=$ $2 \cdot 24 \times 10^{-24}$ c.c. $)$

If we may take $\delta=0 \cdot 1$, we have $10\left(b_{1}-b_{2}\right)=$ $b_{1}+2 b_{2}$, whence $b_{2} / b_{1}=0 \cdot 75, b_{1}=1 \cdot 2 \alpha=1 \cdot 490 r_{e}^{3}$, $b_{2}=0 \cdot 9 \alpha=1 \cdot 117 r_{e}^{3}$, and $b_{1}-b_{2}=0 \cdot 3 \alpha$.
On the present basis of argument, therefore, I conclude that (1) the four hydrogen halides have equal optical anisotropies, (2) the optical polarization ellipsoids constitute similar solid figures, (3) $b_{2}$ is approximately equal to 75 per cent of $b_{1}$, and (4) $b_{1}$ of $\mathrm{HX}$ is equal to the polarizability of the halogen ion $\mathrm{X}^{-}$, a somewhat surprising result. Dispersion of refractive index is neglected in making the estimates.

Further work on the depolarization and Kerr effects of the hydrogen halides other than hydrogen chloride is desirable to confirm these predictions.

Department of Inorganic Chemistry,

$$
\text { C. H. Douglas Clark. }
$$

University, Leeds. June 3.

${ }^{1}$ C. H. Douglas Clark, Trans. Faraday Soc., 31, 585 (1935) (where $\alpha^{\prime \prime}$ = present a).

Clark, Phil. Mag., (vii.), 19, 476 (1935).

a Clark, Proc. Leeds Phil. Soc., 3, 208 (1936)

M. Born and W. Heisenberg, Z. Phys., 23, 388 (1924)

${ }^{\circ}$ H. A. Stuart, Z. Phys., 55, 358 (1929).

\section{Focal Depth of the Hawke's Bay Earthquake of February 2-3, I93I}

IN the seismological report of the Hawke's Bay earthquake of February $2-3,1931^{1}$, an attempt was made to arrive at a value for the focal depth of the shock. The method used was similar to that developed by Jeffreys ${ }^{2}$ for near earthquakes in western Europe, depending on the apparent delay of the surface wave $P g$. In the Hawke's Bay earthquake, a phase agreeing reasonably well in velocity with $P g$ was observed on the seismograms at Arapuni, Takaka and Wellington, and the mean apparent delay led to a focal depth of 13 miles $(21 \mathrm{~km}$.). On account of the confused nature of the Wellington and Arapuni records, and the lack of precise time on most of the records, it was considered that a definite value for the depth could not be obtained, but that it probably lay between 10 miles and 15 miles $(16-24 \mathrm{~km}$.). In the original interpretation of the Takaka record, the first phase recorded after $P n$ was considered to be $P^{*}$, and the interval between $P n$ and $P g$ was 28 seconds.

In a recent paper ${ }^{3}$, C. G. Dahm, of Saint Louis, U.S.A., had occasion to discuss the focal depth of the Hawke's Bay earthquake, using data from the Takaka seismogram. He found an interval of $7 \cdot 5$ sec. between what he considered to be the phases $P n$ and $\bar{P}$, and states that this agrees with a focal depth of $10 \mathrm{~km}$. (6 miles). Dahm points out that the Takaka data are not conclusive, and after some further considerations, finally arrives at a focal depth of the order of 10-12 km. (6-8 miles).

Having rightly directed attention to the difference between his own value for the depth and that given in the Hawke's Bay earthquake report, Dahm criticises this report, considering that the methods used appear to be based on doubtful assumptions. In view of this criticism, I re-examined the original Takaka seismogram. On both horizontal components the first movement (presumably $P n$ ) is very small and emergent, and the interval before the arrival of the second phase was found to be 8 sec. on the E-W component, and 11 sec. on the $\mathrm{N}-\mathrm{S}$ component. This discrepancy of 3 sec. may be due to the arrival of $P n$ not having been recorded on the E-W com. ponent. On the vertical component, $P n$ is very small, but the interval to the next phase was observed to be about $10 \mathrm{sec}$. The mean interval between $P n$ and the next phase at Takaka therefore appears to 